Check for updates

Cite this: RSC Adv., 2019, 9, 29482

\title{
Effect of blending sewage sludge with coal on combustion and ash slagging behavior
}

\author{
Shuai Guo, (D) Qiyao Yang, Honglin Liang, (D) Deyong Che, Hongpeng Liu \\ and Baizhong Sun*
}

Blending sewage sludge (SS) with Zhundong coal (ZDC) for combustion in coal-fired power plants is a recent approach that can alleviate the shortage of high-quality coal resources and achieve the harmless treatment of SS, while also having a significant influence on combustion and ash slagging. Due to the high content of alkali and alkaline earth metals (AAEMs) in ZDC, its combustion ash has a strong likelihood of slagging. This study aims to investigate the effect of blending SS with ZDC on combustion and ash slagging. Thermogravimetry (TG) results indicate that blending with SS could lower the ignition and burnout temperatures of ZDC. With an increase in the ratio of sludge, the comprehensive combustion index (S) first increases and then decreases, showing that blending SS with ZDC in an appropriate proportion could improve the overall combustion. Through the analysis of the interaction, it is confirmed that SS and ZDC could complement each other during co-combustion due to their different components. X-ray fluorescence (XRF) was used to test the ash components of different blending ratios $(10-30 \%)$ and combustion temperatures $\left(800-1100{ }^{\circ} \mathrm{C}\right)$. Slagging indices including alkali acid ratio $(B / A)$, silicon ratio $(G)$, and silica-alumina ratio $\left(\mathrm{SiO}_{2} / \mathrm{Al}_{2} \mathrm{O}_{3}\right)$ were also calculated. The results suggest that the slagging behavior of ZDC is greatly reduced even if the blending ratio is only $10 \%$. However, with an increase in the blending ratio, the effect on slagging gradually weakens. Considering the dual influence of SS blending on combustion and slagging, this study assumes the optimal blending ratio of $20 \%$. Influenced by the components of the combustion ash, $B / A$ and $\mathrm{SiO}_{2} / \mathrm{Al}_{2} \mathrm{O}_{3}$ are more suitable for evaluating the slagging tendency of ash; however, there is great deviation in the results for $G$. This research is beneficial to coal-fired power plants for the selection of operation parameters during co-combustion with SS.

\author{
Received 5th June 2019 \\ Accepted 12th September 2019 \\ DOI: $10.1039 / c 9 r a 04243 a$ \\ rsc.li/rsc-advances
}

\section{Introduction}

Coal is one of the primary sources for the production of energy, and is likely to remain so for many years. With developing societies the demand for electricity is increasing, and highquality coal resources have been exhausted. The exploitation and utilization of low-rank coal is therefore necessary. Coal contains varying amounts of AAEMs, which are more prominent in low-rank coal such as Victoria brown coal and ZDC. ${ }^{\mathbf{1 , 2}}$ For example, ZDC (Xinjiang, China), with a calorific value of 18-22 MJ kg ${ }^{-1},{ }^{3}$ has a high volatile content and a low ash content which means that it ignites easily. ZDC contains large amounts of $\mathrm{Na}$; the proportion of $\mathrm{Na}_{2} \mathrm{O}$ in ash can reach as high as $5.73 \% .^{4}$ Most of the $\mathrm{Na}$ in such coal volatilizes during combustion, and then reacts with $\mathrm{SO}_{3}$ to create sulfate products with a low melting point. These products condense onto the heated surfaces in coal boilers to form a bonding layer which attracts the combustion ash. Both ash and slagging accumulate

School of Energy and Power Engineering, Northeast Electric Power University, Jilin 132000, China.E-mail: sunbaizhong@126.com in this way, leading to severe problems that endanger the normal operation of boilers such as the blasting of the heated surface. ${ }^{5,6}$

Several researchers have carried out detailed studies concerning the migration and transformation of AAEMs in ZDC. Zhang et $a .^{7}$ studied how the Na-rich components in ZDC change at different temperatures. The results suggested that the ashing temperature had a significant influence on the content and appearance of $\mathrm{Na}$ in the ash and the total content of $\mathrm{Na}$ and $\mathrm{Cl}$ decreased with an increase in temperature. $\mathrm{Xu}$ et al. ${ }^{8}$ studied the conversion of components containing $\mathrm{Na}$ during the pyrolysis of demineralized ZDC using a fixed-bed reactor. The results showed that carboxylic acid-soluble $\mathrm{Na}$ is converted to a water-soluble form at $400-600{ }^{\circ} \mathrm{C}$ and is released in the form of water-soluble $\mathrm{NaCl}$ at above $600{ }^{\circ} \mathrm{C}$. This then reacts with the mineral elements or carbon skeleton in the coal to form insoluble components which contain Na. Studies by Manzoori et al. ${ }^{9}$ also showed that the $\mathrm{NaCl}$ found in low-rank coal underwent decomposition and reacted with other compounds during combustion, resulting in the release of $\mathrm{Na}$ and $\mathrm{Cl}$ in different proportions. Organic components containing $\mathrm{Ca}$ and $\mathrm{Mg}$ were 
also found to react with the Na-rich components to form acidinsoluble compounds. Song et al. ${ }^{10}$ also researched the conversion characteristics of the Na found in ZDC. The results showed that Na usually formed aluminosilicate in ash. When $\mathrm{SO}_{2}$ was present, the gaseous Na-containing components react with it to form $\mathrm{Na}_{2} \mathrm{SO}_{4}$. Wang et al. ${ }^{11}$ conducted studies on the depositional characteristics of ZDC ash. The results inferred that with an increase in combustion temperature, components containing $\mathrm{Na}$ underwent a series of changes. At $400-800{ }^{\circ} \mathrm{C}$, $80 \%$ of the $\mathrm{Na}$ and $100 \%$ of the Cl were released. At $800-1000{ }^{\circ} \mathrm{C}$, the remaining $\mathrm{Na}$ was also released, and the release of $\mathrm{S}$ was initiated. At $1000-1200{ }^{\circ} \mathrm{C}$, with the decomposition of the sulfate, the remaining $\mathrm{S}$ was completely released. The ash deposition experiments indicated that the $\mathrm{Na}$ in ZDC was mainly released in the form of gaseous components, which were then deposited on the heated surface in the form of gaseous sulfate. Song et al. ${ }^{12}$ studied the corrosion of the heating surface and the slagging process in a circulating fluidized bed (CFB) during ZDC combustion. The results suggested that due to the presence of $\mathrm{NaCl}$, any $\mathrm{Fe}$ in the heated surface became unstable. The presence of $\mathrm{Fe}_{2} \mathrm{O}_{3}, \mathrm{Na}_{2} \mathrm{O}$, and sulfate accelerated the corrosion of the heated surface. Elements such as $\mathrm{Ca}, \mathrm{Na}, \mathrm{Fe}, \mathrm{S}$, $\mathrm{Si}, \mathrm{Mg}$ in the combustion ash were enriched in the form of lowmelting sulfates, silicates, and other compounds which also resulted in the deposition of slagging on the heated surface.

Blending is an effective method for the alleviation of the slagging problem caused by the release of AAEMs during the combustion of low rank coal. Liu et al. ${ }^{13}$ studied the cocombustion between ZDC and Shenhua coal in a $30 \mathrm{~kW}$ CFB. The results suggested that if the ratio of Shenhua coal to ZDC is increased, the presence of silicon and aluminosilicate decreased the deposition of ZDC ash by capturing the AAEMs. The best blending ratio was found to be $20 \%$. Li et al. ${ }^{14}$ discussed the characteristics of ash deposition during the cocombustion of ZDC and Australian bituminous coal in a drop tube furnace. The results demonstrated that with a higher ratio of Australian bituminous coal to ZDC, the molten mineral content gradually decreased and the refractory quartz and mullite content gradually increased, indicating that blending with bituminous coal could lower the slagging produced by ZDC. When the blending ratio exceeded $40 \%$, it was not affected by changes in temperature, indicating that the ash had a strong anti-sintering property and was not prone to slagging. Zhou et $a l .{ }^{15}$ studied the effects of various types of biomass ash on the sintering properties of ZDC ash. The results showed that corn stalk and rice husk ash could promote the sintering performance of ZDC ash, while wood ash had the opposite effect, as the AAEMs in the ZDC reacted with the biomass ash to create refractory products. The above studies indicate that blending can effectively alleviate slagging during the combustion of highAAEMs coal. There are several other substances that can be blended with low-rank coal, such as SS. As the by-product of sewage treatment, the disposal of SS is always problematic. ${ }^{\mathbf{1 6}}$ If sludge is not handled properly, personal and even social safety can be threatened. ${ }^{17}$ Therefore, the proper treatment of SS is critical. So far, methods using heat treatment are currently considered to be the most thorough. After incineration, the volume of the sludge is significantly reduced, utilizing the heat. The residue after incineration can also be recycled. ${ }^{18,19}$

Sludge has a high volatile content and a significant calorific value and is therefore often used in co-combustion. ${ }^{20,21}$ Deng et al. ${ }^{22}$ studied the co-combustion of SS with biomass using thermogravimetry (TG) analysis. The results showed that the addition of biomass at $280-390^{\circ} \mathrm{C}$ had a negative impact on combustion, but at $390-620^{\circ} \mathrm{C}$ the impact became positive. Ayse et al. ${ }^{23}$ added SS to coal at different proportions during combustion, with results suggesting that the higher the proportion of sludge added, the lower the combustion efficiency. However, the influence from this effect is relatively insignificant, as the efficiency only decreased from $99.5 \%$ to $97.5 \%$ with an increase of $5 \%$ to $30 \%$ to the proportion of sludge. Otero et al. $^{24}$ conducted experiments on the co-combustion characteristics of SS and anthracite in different proportions using TG. Kinetic analysis was carried out using Ozawa-Flynn-Wall and Vyazovkin methods, respectively. The results showed that when the proportion of sludge added was less than $10 \%$, the co-combustion characteristics were similar to those of burning anthracite alone. Folgueras and Park et al. ${ }^{25,26}$ also obtained the similar results. Park et al. ${ }^{26}$ suggested that when the proportion of SS is below $20 \%$, the co-combustion characteristics were similar to that of coal, with similar activation energies. Above all, it indicates that under certain conditions, the blending of SS does not affect the behavior of coal during combustion.

SS has high ash content, which contains a large amount of inorganic salts. Wang et $a .^{27}$ studied the behavior of mineral transformation during the co-combustion of SS and lignite. The results showed that when the SS blending ratio is $10 \%$, minerals such as albite, pyroxene and anorthite were produced. Hao et al. ${ }^{28}$ researched the interaction between SS and anthracite during cocombustion with regards to the combustible conversion rate, ash morphology, and composition changes. The results showed that combustion ash mainly consists of compounds such as $\mathrm{SiO}_{2}, \mathrm{Al}_{2} \mathrm{O}_{3}$, $\mathrm{CaSO}_{4}$, and $\mathrm{Fe}_{2} \mathrm{O}_{3}$. An increase in combustion temperature could promote the agglomeration of ash. Wang et al. ${ }^{29}$ studied the sintering characteristics and mineral conversion behavior of SS ash at different temperatures. The results showed that the initial melting temperature of SS ash with a high $\mathrm{Al}$ content was higher than $1100{ }^{\circ} \mathrm{C}$, with major constituents that include corundum, quartz, and silicates containing $\mathrm{Ca}$ and $\mathrm{Al}$. Studies concerning the effects of SS blending on the slagging characteristics of wood particles was also carried out. The results indicated that SS could prevent the slagging of wood particles during combustion. Ash components of low-melting silicate were found to be converted to high-melting Cacontained silicate, corundum, nepheline, and other such compounds. $^{30}$ The above studies all indicate that during the combustion of SS together with other substances, the components interact and affect the composition of the ash produced, thus initiating different slagging properties. It is therefore assumed that blending low-grade coal with SS could reduce slagging.

Influenced by the source and treatment, some SS contains $\mathrm{N}$ and $\mathrm{P}$, which ultimately renders it acidic. Studies have indicated that components in the sludge that contain $\mathrm{P}$ could fix the $\mathrm{K}$ and $\mathrm{Na}{ }^{31-33}$ Based on the results from previous research, in this study SS is blended with ZDC during combustion, with the intent of preventing slagging on the heated surface that is 
caused by the release of AAEMs, ${ }^{34}$ while also solving the problem of SS pollution. In order to ensure the safe operation of a boiler, an appropriate blending proportion for SS needs to be determined. If the ratio is not suitable, slagging and the deposition of ash on the furnace and the heated surface could be increased. ${ }^{35}$ Therefore, the means of deciding a suitable blending ratio for SS during ZDC combustion is discussed in this paper.

It is evidence from the foregoing that several previous studies focused on the co-combustion characteristics between SS and coal, without examination of the ash slagging, especially for the coal with high AAEM contents. To bridge this gap in the literature, systematic techniques were used in the present study to investigate the effects of blending SS with ZDC on combustion and slagging behaviors, TG and muffle furnace were used to carry out experiments using different proportions of SS $(10 \%$, $20 \%$ and $30 \%$ ). The characteristic parameters, such as ignition and burnout temperature, comprehensive combustion index etc., were considered to evaluate the effects of the addition of SS. The interaction between SS and ZDC during combustion was analyzed. Besides, the components of co-combustion ash were measured using XRF technique, and the evaluation indices for slagging tendency were also calculated. Based on the findings, this work aims to determine an appropriate ratio for blending that could minimize slagging behaviors without affecting the combustion behaviors of coal.

\section{Experimental}

\subsection{Materials}

The SS used in the experiments was taken from Huanjia Environmental Protection Co., Ltd., Jilin City, China. The sludge consisted of $55.3 \%$ industrial sludge and $44.7 \%$ municipal sludge. The ZDC was from Zhundong coalfied which is the largest integrated coal basin newly found in China. The SS and ZDC were initially dried at $105{ }^{\circ} \mathrm{C}$ for more than $24 \mathrm{~h}$.

The sample was then pulverized in a small mill and sieved using a 80 mesh screen with a pore size of $178 \mu \mathrm{m}$, and the materials with the diameter less than $178 \mu \mathrm{m}$ were used in the experiments. The proximate and ultimate analysis results are shown in Table 1 . The SS and ZDC were mixed well with different ratios. The proportion of SS added was $0 \%, 10 \%, 20 \%$, $30 \%$ and $100 \%$ in samples $\mathrm{S}_{1}-\mathrm{S}_{5}$, respectively. The blended samples were then sealed and stored at $4{ }^{\circ} \mathrm{C}$.

Ash samples from the combustion were prepared using $\mathrm{S}_{1}-\mathrm{S}_{5}$ at different temperatures $\left(800{ }^{\circ} \mathrm{C}, 900{ }^{\circ} \mathrm{C}, 1000{ }^{\circ} \mathrm{C}, 1100{ }^{\circ} \mathrm{C}\right)$ in a muffle furnace. To achieve this, the experimental samples were evenly spread on the bottom of the quartz boat at less than $0.15 \mathrm{~g} \mathrm{~cm}^{-2}$. When the furnace reached the desired temperature, the boat was placed into the furnace. A gap of approximately $15 \mathrm{~mm}$ was left in the furnace door for air circulation to achieve the complete combustion. Ash samples were weighed at regular intervals until changes in the measured weight did not exceed $0.1 \%$. Finally, the ash samples were naturally cooled and then stored.

\subsection{TG experiments}

The combustion characteristics of samples $\mathrm{S}_{1}-\mathrm{S}_{5}$ were investigated using a TG analyzer (TGA/SDTA851 ${ }^{\mathrm{e}}$, METTLER-TOLEDO, Switzerland). Samples of $10 \mathrm{mg} \pm 0.5 \mathrm{mg}$ were spread evenly on the bottom of a crucible to minimize any errors caused by changes in temperature or gradients in air concentration. The temperature used for the experiment ranged between room temperature and $900{ }^{\circ} \mathrm{C}$. An air atmosphere was adopted with a gas flow rate of $50 \mathrm{ml} \mathrm{min}{ }^{-1}$. In order to study the effects of blending SS with ZDC on the characteristics of combustion. At heating rates of $10{ }^{\circ} \mathrm{C} \min ^{-1}, 20{ }^{\circ} \mathrm{C} \min ^{-1}, 30{ }^{\circ} \mathrm{C} \min ^{-1}$, and $40{ }^{\circ} \mathrm{C} \min ^{-1}$, The activation $\operatorname{energy}\left(E_{\mathrm{m}}\right)$ was calculated with a conversion rate $(\alpha)$ of $0.1-0.9$ in increments of 0.1 , and the mean was taken as the final result.

\subsection{Co-combustion ash composition tests}

The components of the combustion ash in $\mathrm{S}_{1}-\mathrm{S}_{5}$ were tested using an X-ray fluorescence spectrometer (XRF, S8TIGER, Bruker, Germany). Alkaline oxides found via this method include $\mathrm{CaO}, \mathrm{Fe}_{2} \mathrm{O}_{3}, \mathrm{MgO}, \mathrm{Na}_{2} \mathrm{O}$ and $\mathrm{K}_{2} \mathrm{O}$, and acidic oxides include $\mathrm{SiO}_{2}, \mathrm{Al}_{2} \mathrm{O}_{3}, \mathrm{P}_{2} \mathrm{O}_{5}$ and $\mathrm{TiO}_{2}$. The working voltage of the instrument was $20-60 \mathrm{kV}$ with an angular resolution of $\pm 0.001^{\circ}$. A $2 \mathrm{~g}$ sample from each different ash was placed into an agate mortar to which boric acid was added and mixed. The samples were then compressed into tablets with a smooth surface. In order to prevent contamination of the samples, the mortar and mold was cleaned with absolute ethanol. The samples were tested at least three times, and the mean was taken as the final result.

\section{Results and discussions}

\subsection{TG/DTG analysis}

3.1.1 Combustion without blending. Fig. 1(a) shows the curves for the TG and DTG analysis of the ZDC combustion when heated at a rate of $20{ }^{\circ} \mathrm{C} \mathrm{min}^{-1}$. It can be seen from the DTG curve that the ZDC combustion process can be divided into

Table 1 The proximate and ultimate analysis for ZDC and SS

\begin{tabular}{|c|c|c|c|c|c|c|c|c|c|c|}
\hline \multirow[b]{2}{*}{ Sample } & \multicolumn{5}{|c|}{ Proximate analysis (\%) } & \multicolumn{4}{|c|}{ Ultimate analysis (\%) } & \multirow{2}{*}{$\frac{\text { Heating value }}{Q_{\text {net,ar }}\left(\mathrm{kJ} \mathrm{kg}^{-1}\right)}$} \\
\hline & $\mathrm{C}_{\mathrm{ad}}$ & $\mathrm{H}_{\mathrm{ad}}$ & $\mathrm{O}_{\mathrm{ad}}$ & $\mathrm{N}_{\mathrm{ad}}$ & $\mathrm{S}_{\mathrm{ad}}$ & $\mathbf{M}_{\mathrm{ad}}$ & $\mathrm{V}_{\mathrm{ad}}$ & $\mathrm{A}_{\mathrm{ad}}$ & $\mathrm{FC}_{\mathrm{ad}}$ & \\
\hline SS & 18.03 & 2.85 & 13.81 & 2.07 & 0.60 & 3.84 & 32.66 & 58.80 & 4.70 & 8200.29 \\
\hline
\end{tabular}




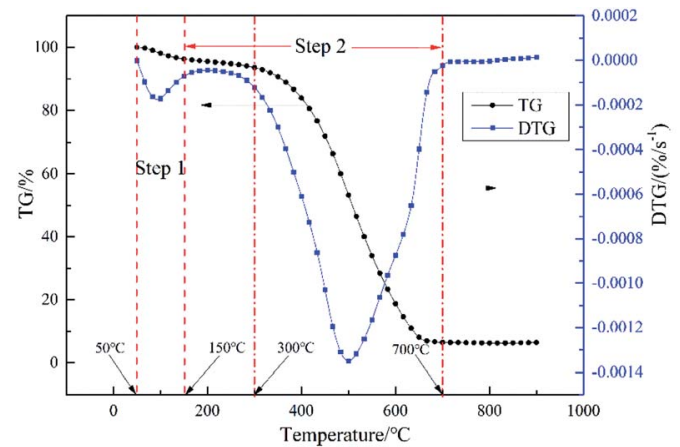

a)

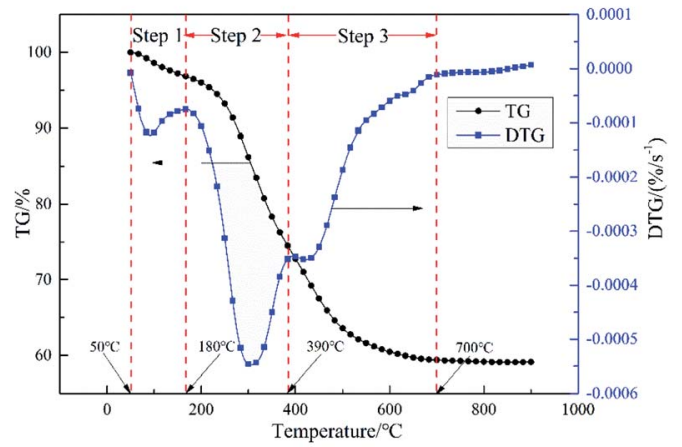

b)

Fig. 1 TG and DTG analysis for ZDC and SS combustion: (a) ZDC; (b) SS.

two stages, it is also verified by Qi et al. ${ }^{36}$ The first is the stage during which moisture evaporates at 50-150 ${ }^{\circ} \mathrm{C}$. After that, devolatilization and fixed carbon combustion occurs in the second stage at $150-700{ }^{\circ} \mathrm{C}$. This is the main stage of ZDC combustion, during which the weight loss accounts for about $88 \%$ of the total. It can be seen from Table 1 that there is almost twice the amount of fixed carbon as there is volatiles in ZDC, and the volatile components burn faster. Therefore, no obvious generation or combustion of volatiles can be seen in Fig. 1(a). The second stage mainly refers to the combustion of fixed carbon.

Fig. 1(b) illustrates the TG and DTG curves for SS combustion at a heating rate of $20{ }^{\circ} \mathrm{C} \mathrm{min}{ }^{-1}$. It can be seen from the DTG curve that the process of SS combustion can be divided into three stages, ${ }^{37}$ namely water evaporation $\left(50-180{ }^{\circ} \mathrm{C}\right)$, devolatilization and combustion (180-390 ${ }^{\circ} \mathrm{C}$ ), and fixed carbon combustion $\left(390-700{ }^{\circ} \mathrm{C}\right)$. The weight loss in the second stage accounts for about $52 \%$ which is the main stage in the combustion of SS. This is consistent with Table 1 , in that the volatile content $(32.66 \%)$ is much higher than that of fixed carbon $(4.7 \%)$ in SS. In addition, compared with ZDC, the peak width of the DTG curve for the main combustion stage of SS is narrower, which may be due to its high volatile content. The weight loss at the third stage accounts for about 39\%, and the combustion rate at this stage obviously slows down. A high ash content within SS could adhere to the fixed carbon surface and prevent combustion. Moreover, combustion of volatiles consumes significant amounts of $\mathrm{O}_{2}$, so the fixed carbon has limited access to $\mathrm{O}_{2}$ until the volatiles are completely burned. ${ }^{38}$ Therefore, there is a short plateau between the second and third stage. It can be seen that the combustion of volatiles plays an important role during SS combustion. It is assumed that ZDC and SS could complement each other during co-combustion, which is discussed in the following part.

3.1.2 Effect of heating rate on co-combustion. The heating rate has significant effects on the combustion process, and instantaneous heating occurs in actual boiler for fuels. Fig. 2 shows the TG and DTG curves for the combustion of sample $\mathrm{S}_{2}$ at different heating rates. It can be seen from Fig. 2(a) that with an increase in the heating rate, the TG curve gradually moves to the area associated with high temperature, since the ignition temperature drops while the burnout temperature rises. This is because with the increase in the heating rate, the temperature gradient between the surface and the inside of the combustibles gradually decreases, contributing to a rapid devolatilization during the initial combustion stage, and the ignition temperature drops accordingly. It is known that the higher the heating rate, the higher the temperature rise during the whole combustion. It is also reflected in the increase of burnout temperature. In general, the combustion process could move to the high temperature area with the increase in heating rate. It can be seen from the DTG curve in Fig. 2(b) that with the increase in the heating rate, the maximum weight loss peak gradually moves to the high temperature area, which is consistent with the above result.

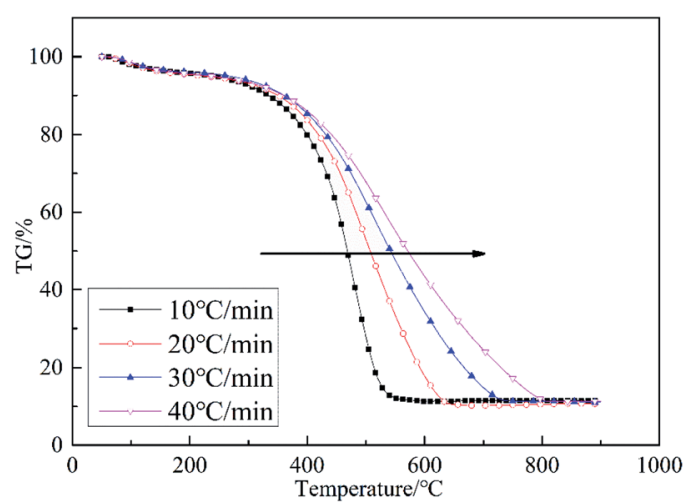

a)

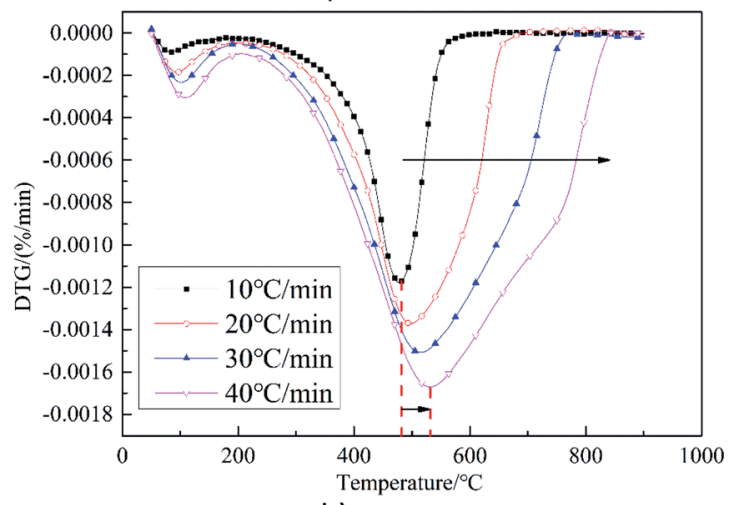

b)

Fig. 2 TG and DTG analysis for sample S2 combustion at different heating rates: (a) TG; (b) DTG. 
The rate of maximum weight loss increases with the increase in the rate of heating, which is consistent with the widening phenomenon between ignition and burnout temperature when the heating rate increases. Samples are impacted by the high temperature over a short time, so the reactions are enhanced. ${ }^{39}$

3.1.3 Influence of blending ratio on combustion. Fig. 3 shows the TG and DTG curves for the combustion of samples $\mathrm{S}_{1}-\mathrm{S}_{5}$ at the same heating rate $\left(30^{\circ} \mathrm{C} \mathrm{min}^{-1}\right)$. It can be seen from Fig. 3(a) that the TG curve for the co-combustion is similar to that of ZDC. This is because the SS blending ratio in the experiments is no more than $30 \%$; therefore the combustion characteristics remain similar to ZDC. ${ }^{36}$ With an increase in the blending ratio, due to the high ash content in SS, the mass retention of ash increases, ${ }^{36}$ and the TG curve moves to a low temperature area at the initial stage of reaction, but moves to a high temperature area later. The phenomenon is most obvious in the case of sample $\mathrm{S}_{4}$, with the blending ratio of $30 \%$. The TG curve for this sample has a significant junction with the other samples at approximately $500{ }^{\circ} \mathrm{C}$. This is because SS contains more volatiles than that of ZDC, promoting the ignition and accelerating the reaction. However, the ash content of SS is also higher than that of ZDC, and the ash adheres to the char surface, inhibiting the reaction at later stage. The tendency is the same in Fig. 3(b), where the rate of weight loss initially increases, but decreases with the increase in the blending ratio. The maximum rate of weight loss also gradually decreases with

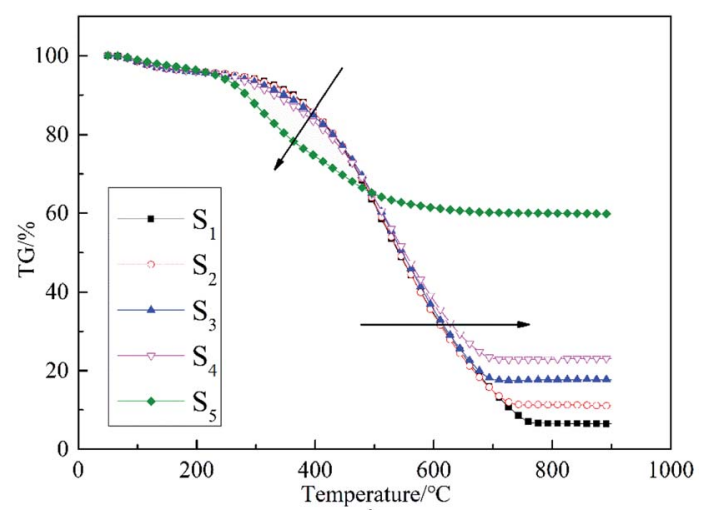

a)

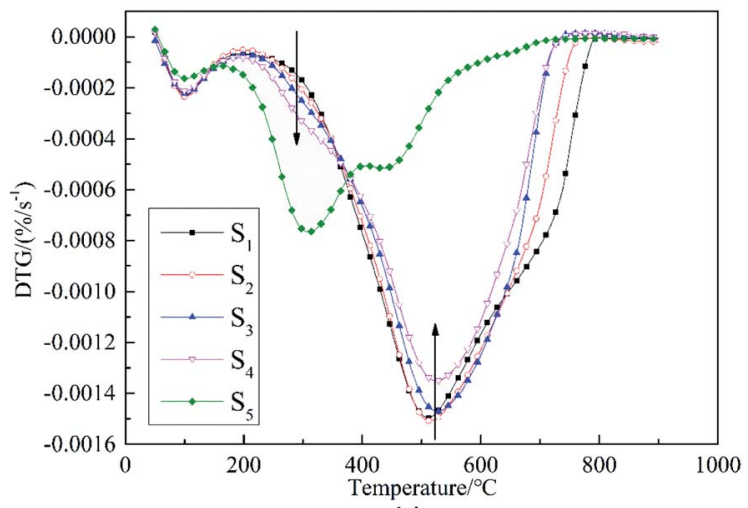

b)

Fig. 3 TG and DTG analysis for samples S1-S5 combustion at different blending ratios: (a) TG; (b) DTG. an increase of the blending ratio. ZDC has high char content, and blending with SS causes the relative content of char to decrease, so the weight loss rate also decreases correspondingly. The temperature corresponding to the maximum weight loss rate will gradually increase, because the heat from the combustion of the volatiles within SS contributes to the char combustion. ${ }^{40}$

\subsection{Analysis of the combustion characteristic parameters}

Table 2 shows the parameters of the combustion characteristic

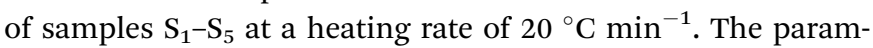
eters include ignition temperature $\left(T_{\mathrm{i}}\right)$, burnout temperature $\left(T_{\mathrm{h}}\right)$, ignition index $(C)$, stable-combustion index $(\mathrm{SI})$ and comprehensive combustion index $(S)$. It is apparent that when compared with ZDC, SS has lower $T_{\mathrm{i}}$ and $T_{\mathrm{h}}$ and a shorter duration of combustion. This indicates that SS contains less combustibles, but is more inflammable. High concentrations of $C$ also demonstrate the property. This is consistent with the conclusion of Mikulcic et al. ${ }^{\mathbf{4 1}}$ that biomass is more combustible than coal. In addition, the maximum and average combustion speeds $\left((\mathrm{d} w / \mathrm{d} t)_{\max },(\mathrm{d} w / \mathrm{d} t)_{\text {mean }}\right)$ are low, indicating that the combustion is not so intensive as that of ZDC. The corresponding SI is also higher. With respect to the above factors, levels of $S$ during SS combustion are also lower than that of ZDC. Table 2 also shows that with an increase of the blending ratio of SS with ZDC, the $T_{\mathrm{i}}$ and $T_{\mathrm{h}}$ are both reduced. When the blending ratio is $10-20 \%$, when compared with coal without any blending, $(\mathrm{d} w / \mathrm{d} t)$ mean and $S$ both increases. However, when the blending ratio is $30 \%,(\mathrm{~d} w / \mathrm{d} t)$ mean, $C$, SI, and $S$ are all lower than those of coal without blending. The above results indicate that blending of SS with ZDC in an appropriate proportion can improve the overall combustion. From the experimental conditions in this paper, the blending ratio should not exceed $20 \%$. The result is very similar to Qi et $a{ }^{36}{ }^{36}$ who indict that high combustion performance occurs at the sludge blending ratio of $25 \%$.

Table 3 shows the parameters of the combustion characteristics of sample $S_{3}$ at different heating rates. It can be seen that with an increase in the rate of heating, the $T_{\mathrm{i}}$ gradually decreases but the $T_{\mathrm{h}}$ increases, ${ }^{42}$ which is consistent with Fig. 3(a). Indices of $(\mathrm{d} w / \mathrm{d} t)_{\max },(\mathrm{d} w / \mathrm{d} t)_{\text {mean }}, C$, SI, and $S$ all increase, indicating that the increase in heating rate could enhance combustion.

\subsection{Activation energy analysis}

Kinetic parameters were calculated using the methods developed by Flynn-Wall-Ozawa (FWO) and Friedman (FM). ${ }^{43}$ Fig. 4 shows the curve of $\ln [(\mathrm{d} \alpha / \mathrm{d} t) \beta]$ vs. $1000 / T$ and $\ln \beta$ vs. $1000 / T$ for sample $\mathrm{S}_{5}$ at different heating rates under the given conversion rates. The results are used to determine the slope and intercept under different $\alpha$. The $E_{\mathrm{m}}$ is then calculated according to the slope and intercept of the regression curve. The correlation coefficients of the fitting results are all greater than 0.98 . The results for the calculation of $E_{\mathrm{m}}$ at different $\alpha$ are shown in Tables 4 and 5, and the results for the average $E_{\mathrm{m}}$ are shown in 
Table 2 The combustion characteristic parameters of samples $\mathrm{S}_{1}-\mathrm{S}_{5}$ at a heating rate of $30^{\circ} \mathrm{C} \mathrm{min}^{-1}$

\begin{tabular}{|c|c|c|c|c|c|c|c|c|c|}
\hline Heating rate $\left({ }^{\circ} \mathrm{C} \min ^{-1}\right)$ & Sample & $T_{\mathrm{i}}\left({ }^{\circ} \mathrm{C}\right)$ & $T_{\mathrm{h}}\left({ }^{\circ} \mathrm{C}\right)$ & $T_{\max }\left({ }^{\circ} \mathrm{C}\right)$ & $\begin{array}{l}(\mathrm{d} w / \mathrm{d} t)_{\max } \\
(\% / \mathrm{min})\end{array}$ & $\begin{array}{l}(\mathrm{d} w / \mathrm{d} t)_{\text {mean }} \\
(\% / \mathrm{min})\end{array}$ & $C, 10^{-5}$ & SI, $10^{-5}$ & $S, 10^{-7}$ \\
\hline \multirow[t]{5}{*}{30} & $\mathrm{~S}_{1}$ & 392 & 745 & 509 & 8.97 & 6.55 & 5.84 & 4.49 & 5.14 \\
\hline & $\mathrm{S}_{2}$ & 391 & 716 & 514 & 9.04 & 6.80 & 5.91 & 4.51 & 5.62 \\
\hline & $\mathrm{S}_{3}$ & 391 & 682 & 527 & 8.83 & 6.83 & 5.77 & 4.28 & 5.40 \\
\hline & $\mathrm{S}_{4}$ & 383 & 678 & 525 & 8.10 & 6.14 & 5.52 & 4.03 & 4.95 \\
\hline & $\mathrm{S}_{5}$ & 237 & 646 & 310 & 6.12 & 2.50 & 10.90 & 8.33 & 4.22 \\
\hline
\end{tabular}

Fig. 5. It is apparent that the trends using the two methods are basically the same, proving the reliability of the methods.

It can be seen from Tables 4 and 5 that the $E_{\mathrm{m}}$ of samples $\mathrm{S}_{1}-$ $\mathrm{S}_{4}$ tends to decrease generally with an increase in $\alpha$, because the combustion of volatiles within the ZDC provides heat for the combustion of char. This provides sufficient energy for the subsequent reaction. Therefore, $E_{\mathrm{m}}$ decreases during the reaction. ${ }^{44}$ Meanwhile, as can be seen from Fig. $5, E_{\mathrm{m}}$ tends to increase slightly with an increase in the SS blending ratio, indicating that blending with SS could affect the combustion of ZDC. With the increase in the blending ratio, the influence becomes more obvious. Under the experimental conditions in this paper, when the blending ratio reaches $30 \%$, the cocombustion characteristics are generally closer to the combustion of SS alone. For example, when $\alpha=10 \%$, the $E_{\mathrm{m}}$ of sample $\mathrm{S}_{4}$ first increases and then decreases; when $\alpha=20 \%$, the $E_{\mathrm{m}}$ of sample $S_{2}$ and $S_{3}$ both decrease with the increase of $\alpha$. In addition, compared with samples $\mathrm{S}_{1}-\mathrm{S}_{4}$, the $E_{\mathrm{m}}$ of sample $\mathrm{S}_{5}$ significantly increases (see Fig. 5). Contrary to the results for samples $\mathrm{S}_{1}-\mathrm{S}_{4}$, the $E_{\mathrm{m}}$ of sample $\mathrm{S}_{5}$ increases with the increase of $\alpha$ (see Tables 4 and 5), illustrating the different combustion characteristics of SS and ZDC. The $E_{\mathrm{m}}$ estimated for the cocombustion of ZDC with SS approached that of ZDC, which indicts that co-combustion of ZDC with SS is a feasible management option for such waste. ${ }^{45}$

\subsection{Interaction analysis during co-combustion}

The above results show that blending of SS with ZDC could influence the parameters of the combustion characteristics as well as $E_{\mathrm{m}}$, improving the combustion performances at low sludge blending ratio, that is interaction occurs during cocombustion. ${ }^{36}$ In order to analyze the interaction, the experimental and theoretical values of DTG are compared. ${ }^{46}$ The theoretical values are calculated using eqn (1).

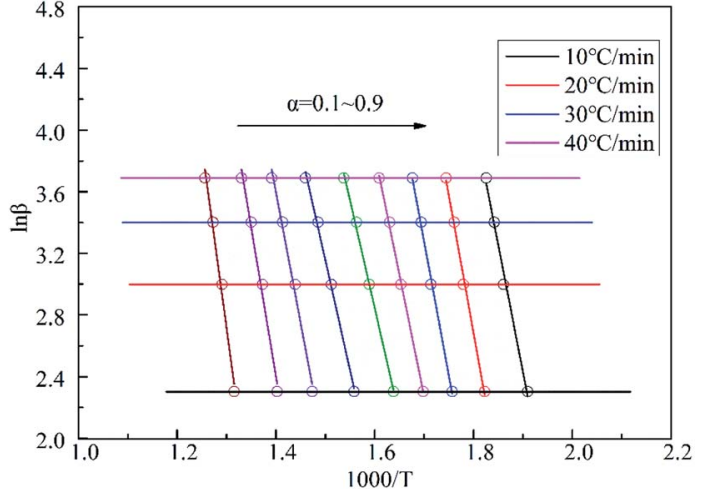

a)

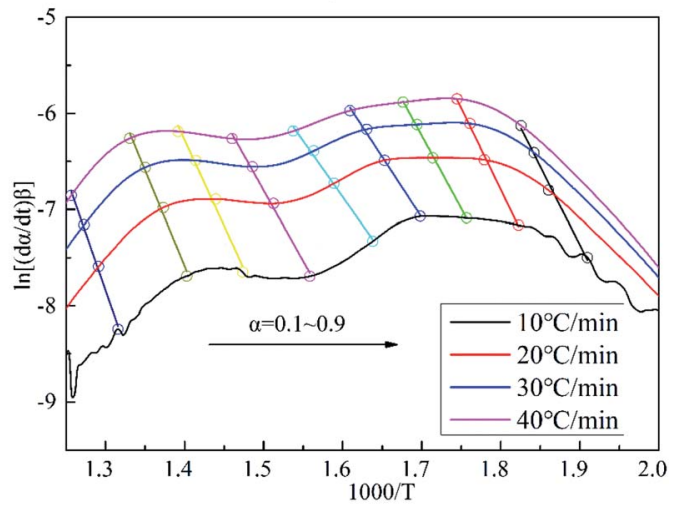

b)

Fig. 4 The fitting curves obtained for sample S5 combustion using: (a) FWO method; (b) FM method.

$$
\left(\frac{\mathrm{d} M}{\mathrm{~d} t}\right)_{\text {calculated }}=x_{1}\left(\frac{\mathrm{d} M}{\mathrm{~d} t}\right)_{1}+x_{2}\left(\frac{\mathrm{d} M}{\mathrm{~d} t}\right)_{2}
$$

In the equation, $x_{1}$ and $x_{2}$ are the percentages of SS and ZDC in the mixed sample by weight $(\%)$, respectively, and $(\mathrm{d} M / \mathrm{d} t)_{1}$ and

Table 3 The combustion characteristic parameters of sample $S_{3}$ at different heating rates

\begin{tabular}{|c|c|c|c|c|c|c|c|c|c|}
\hline Sample & $\begin{array}{l}\text { Heating rate } \\
\left({ }^{\circ} \mathrm{C} \min ^{-1}\right)\end{array}$ & $T_{\mathrm{i}}\left({ }^{\circ} \mathrm{C}\right)$ & $T_{\mathrm{h}}\left({ }^{\circ} \mathrm{C}\right)$ & $T_{\max }\left({ }^{\circ} \mathrm{C}\right)$ & $\begin{array}{l}(\mathrm{d} w / \mathrm{d} t)_{\max } \\
(\% / \mathrm{min})\end{array}$ & $\begin{array}{l}(\mathrm{d} w / \mathrm{d} t)_{\text {mean }} \\
(\% / \mathrm{min})\end{array}$ & $C, 10^{-5}$ & SI, $10^{-5}$ & $S, 10^{-7}$ \\
\hline \multirow[t]{4}{*}{$\mathrm{S}_{3}$} & 10 & 399 & 540 & 474 & 6.60 & 4.31 & 4.14 & 3.49 & 3.31 \\
\hline & 20 & 395 & 624 & 504 & 7.63 & 5.69 & 4.89 & 3.83 & 4.46 \\
\hline & 30 & 391 & 682 & 527 & 8.83 & 6.83 & 5.77 & 4.28 & 5.41 \\
\hline & 40 & 384 & 780 & 539 & 9.31 & 6.87 & 6.32 & 4.50 & 5.57 \\
\hline
\end{tabular}


Table 4 The $E_{m}$ for samples $S_{1}-S_{5}$ combustion at different conversion rates using FWO method

\begin{tabular}{|c|c|c|c|c|c|}
\hline \multirow{2}{*}{$\begin{array}{l}\alpha \\
(\%)\end{array}$} & \multicolumn{5}{|c|}{$E_{\mathrm{m}}\left(\mathrm{kJ} \mathrm{mol}^{-1}\right)$} \\
\hline & $\mathrm{S}_{1}$ & $\mathrm{~S}_{2}$ & $\mathrm{~S}_{3}$ & $\mathrm{~S}_{4}$ & $\mathrm{~S}_{5}$ \\
\hline 10 & 101.93 & 119.90 & 112.61 & 106.47 & 129.38 \\
\hline 20 & 95.70 & 103.30 & 105.55 & 112.64 & 137.03 \\
\hline 30 & 74.69 & 75.81 & 79.43 & 91.76 & 135.03 \\
\hline 40 & 55.72 & 57.23 & 60.18 & 63.33 & 104.53 \\
\hline 50 & 38.42 & 39.97 & 43.01 & 50.14 & 96.77 \\
\hline 60 & 31.36 & 32.75 & 34.78 & 38.45 & 102.10 \\
\hline 70 & 27.95 & 28.44 & 33.27 & 33.20 & 118.55 \\
\hline 80 & 27.20 & 27.59 & 29.66 & 32.96 & 138.42 \\
\hline 90 & 25.81 & 25.38 & 26.86 & 30.05 & 167.13 \\
\hline
\end{tabular}

Table 5 The $E_{\mathrm{m}}$ for samples $\mathrm{S}_{1}-\mathrm{S}_{5}$ combustion at different conversion rates using FM method

\begin{tabular}{lrrrrr}
\hline & \multicolumn{2}{l}{$E_{\mathrm{m}}\left(\mathrm{kJ} \mathrm{mol}^{-1}\right)$} \\
\cline { 2 - 6 }$(\%)$ & \multicolumn{1}{c}{$\mathrm{S}_{1}$} & \multicolumn{1}{c}{$\mathrm{S}_{2}$} & \multicolumn{1}{c}{$\mathrm{S}_{3}$} & \multicolumn{1}{c}{$\mathrm{S}_{4}$} & \multicolumn{1}{c}{$\mathrm{S}_{5}$} \\
\hline 10 & 100.76 & 124.03 & 111.89 & 107.68 & 130.29 \\
20 & 98.33 & 112.24 & 109.57 & 115.74 & 142.21 \\
30 & 90.26 & 97.29 & 99.04 & 104.36 & 137.25 \\
40 & 78.81 & 82.28 & 84.84 & 90.66 & 124.60 \\
50 & 67.49 & 69.24 & 73.21 & 77.22 & 110.75 \\
60 & 57.83 & 58.99 & 61.29 & 66.21 & 112.96 \\
70 & 48.80 & 51.01 & 54.51 & 57.66 & 134.62 \\
80 & 43.10 & 44.57 & 48.06 & 50.90 & 152.44 \\
90 & 40.50 & 39.62 & 42.91 & 45.39 & 186.27
\end{tabular}

$(\mathrm{d} M / \mathrm{d} t)_{2}$ are the rates of weight loss for SS and ZDC (\%/min), respectively. The difference in the values $(\triangle \mathrm{DTG})$ between the experimental and the theoretical values of DTG for different blending ratios are calculated. A positive value means that a promoting effect occurs between them. Otherwise, the effect is inhibitory. The larger the difference in value the stronger the interaction. ${ }^{46} \Delta$ DTG is calculated using eqn (2).

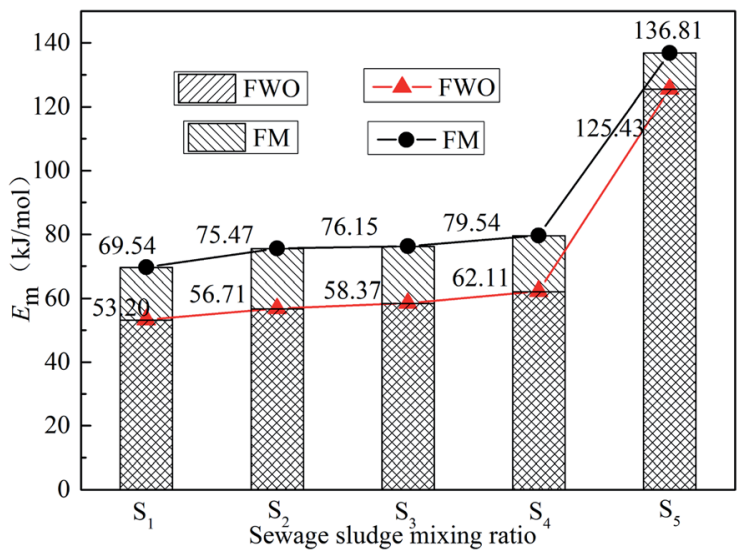

Fig. 5 The average activation energies for samples S1-S5 combustion

$$
\Delta \mathrm{DTG}=\mathrm{DTG}_{\text {experimental }}-\mathrm{DTG}_{\text {calculated }}
$$

Fig. 6(a) shows the results of $\triangle$ DTG during the combustion of samples $\mathrm{S}_{2}-\mathrm{S}_{4}$ at a heating rate of $30{ }^{\circ} \mathrm{C} \mathrm{min}^{-1}$. It can be seen that the trends for change in the three samples are basically the same. The interaction between SS and ZDC is enhanced with the increase in the SS blending ratio. For the same sample, when the temperature is below $150{ }^{\circ} \mathrm{C}$ (dehydration stage), SS could promote combustion. The hydrophilic characteristics of SS could be helpful in removing moisture during ZDC combustion. At $150-350{ }^{\circ} \mathrm{C}, \triangle \mathrm{DTG}$ is almost 0 , indicating that the SS and ZDC do not interact with each other at this stage. At $350-480^{\circ} \mathrm{C}$, SS may be promoting the combustion process to some extent. The greater the blending ratio, the more significant this effect is, which may be caused by the combustion of the volatiles within the SS. At $480-750{ }^{\circ} \mathrm{C}$ the inhibition effect becomes evident due to the high ash content within SS. This phenomenon was similar to the research. ${ }^{46}$ At $750-850{ }^{\circ} \mathrm{C}$, the combustion of SS and ZDC are thought to promote each other. The heat generated by the combustion of the char in the ZDC could promote the combustion of the fixed carbon within the SS. However, no such interaction is observed as the samples almost burn out at above $850{ }^{\circ} \mathrm{C}$. In summary, the interaction between SS and ZDC during co-combustion promotes, inhibits, and then promotes combustion as the temperature increases, which is consistent with the idea of a "complementary" effect during co-combustion.

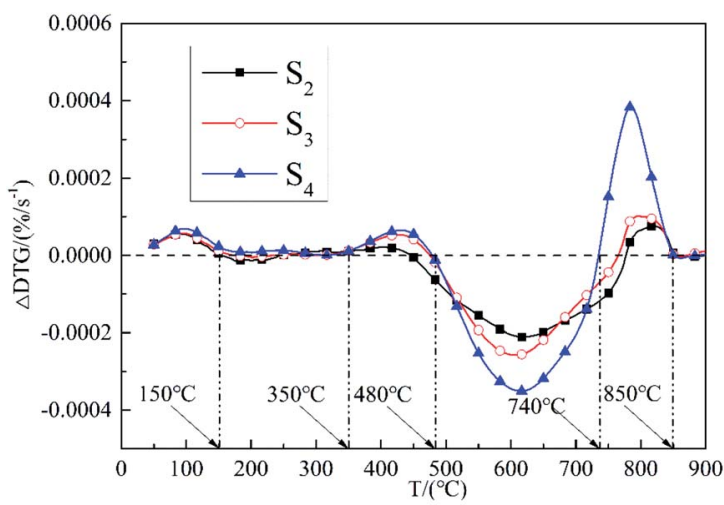

a)

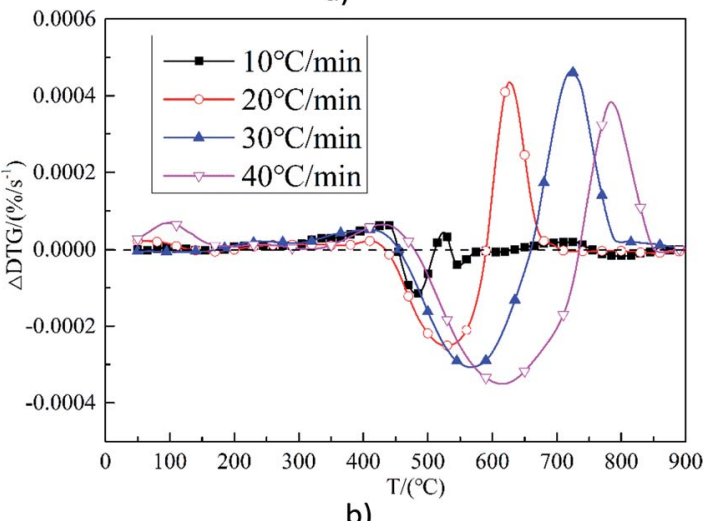

b)

Fig. $6 \Delta$ DTG for the combustion of samples S2-S4 at: (a) $30^{\circ} \mathrm{C} \mathrm{min}^{-1}$; (b) $10-40{ }^{\circ} \mathrm{C} \mathrm{min}^{-1}$. 
Fig. 6(b) shows the results of the $\Delta$ DTG of sample $S_{4}$ at different heating rates. It can be seen that for this sample with the increase of heating rate, the interaction between them becomes evident, and the promoting effect gradually moves to the high temperature area. It can be inferred that there will be strong interactions between them in case of instantaneous heating by continuous fuels feeding in the boiler.

\subsection{An analysis of slagging behavior during co-combustion}

3.5.1 The analysis of ash components. The results of the tests for acidic and alkaline oxide contents within the combustion ash of samples $S_{1}-S_{5}$ at different temperatures are shown in Table 6. It can be seen that the alkaline oxide content is significantly higher than that of the acidic oxide in the combustion ash of ZDC at 800-1100 ${ }^{\circ} \mathrm{C}$. Compared with other types of coal, $\mathrm{ZDC}$ has more $\mathrm{CaO}, \mathrm{MgO}$ and $\mathrm{Na}_{2} \mathrm{O}$, which may be the main reason for its strong slagging behavior. ${ }^{4}$ When blended with $10 \% \mathrm{SS}$, the acidic oxide content is higher than that of alkaline oxide. With an increase in the blending ratio, the gap between the acidic and alkaline oxide content increases. The acidic oxide content is approximately three times greater than that of alkaline oxide in the SS combustion ash, which contains high contents of $\mathrm{SiO}_{2}, \mathrm{Al}_{2} \mathrm{O}_{3}$ and $\mathrm{P}_{2} \mathrm{O}_{5}$ with high melting points, they are considered as refractory minerals. ${ }^{47}$ Therefore, it is assumed that the slagging behavior of ZDC will be greatly weakened by blending with SS. A quantitative analysis of the slagging behavior of co-combustion ash under different conditions is made using various evaluation indices below.

3.5.2 Analysis of the slagging behavior indices. Slagging behavior is usually evaluated using the components of the ash. However, due to the diversity of composition, it is unreasonable to evaluate slagging properties with a single index. Three indices are therefore used in this study; the alkali and acid ration $(B / A)$, the silicon ratio $(G)$, and the silicon and aluminum ratio $\left(\mathrm{SiO}_{2} / \mathrm{Al}_{2} \mathrm{O}_{3}\right){ }^{48}$

(1) $B / A$. The more acidic components the ash contains, the higher the melting point. However, alkaline components have a fluxing action. Therefore, the ratio $(B / A)$ can reflect the slagging tendency. ${ }^{49} B / A$ is the most commonly used evaluation index, and is calculated with eqn (3).

$$
B / A=\frac{\mathrm{Fe}_{2} \mathrm{O}_{3}+\mathrm{CaO}+\mathrm{MgO}+\mathrm{Na}_{2} \mathrm{O}+\mathrm{K}_{2} \mathrm{O}}{\mathrm{SiO}_{2}+\mathrm{Al}_{2} \mathrm{O}_{3}+\mathrm{TiO}_{2}+\mathrm{P}_{2} \mathrm{O}_{5}}
$$

$B$ and $A$ is the percentage of alkaline and acidic oxide content within ash by weight (\%), respectively. The relationship between the value of $B / A$ and slagging behavior is as follows: when $B / A<$ 0.4 , the tendency is towards weak slagging; when $0.4<B / A<0.7$, slagging occurs at a medium level; and when $B / A>0.7$, the amount of slagging is significant. The $B / A$ calculation results for the co-combustion ash at different temperatures and blending ratios are shown in Fig. 7.

It can be seen that ZDC has a strong tendency for slagging, whereas SS has a low tendency. The change in $B / A$ with the SS blending ratio at different temperatures is similar. The slagging of ZDC is reduced significantly even if the blending ratio is only $10 \%$, as the slagging tendency declines from a severe to a medium level. Zhao et al. ${ }^{47}$ obtained the similar result, they indicted that only slight or medium slagging was predicted to occur during co-combustion. Slagging gradually weakens with the increase in blending ratio, the result is very similar to Qi et $a{ }^{36}$ They pointed out that an improvement of the ash fusibility during co-combustion through microtopography change. A large amount of fine particles but no sintering aggregates could be observed for the sludge blending ratio of

Table 6 Ash components for samples $S_{1}-S_{5}$ combustion at different temperatures

\begin{tabular}{|c|c|c|c|c|c|c|c|c|c|c|c|c|}
\hline \multirow[b]{2}{*}{$T\left({ }^{\circ} \mathrm{C}\right)$} & \multirow[b]{2}{*}{ Sample } & \multicolumn{5}{|c|}{ Alkaline oxide content (\%) } & \multirow{2}{*}{$\begin{array}{l}\text { Total } \\
(\%)\end{array}$} & \multicolumn{4}{|c|}{ Acidic oxide content (\%) } & \multirow{2}{*}{$\begin{array}{l}\text { Total } \\
(\%)\end{array}$} \\
\hline & & $\mathrm{CaO}$ & $\mathrm{Fe}_{2} \mathrm{O}_{3}$ & $\mathrm{MgO}$ & $\mathrm{Na}_{2} \mathrm{O}$ & $\mathrm{K}_{2} \mathrm{O}$ & & $\mathrm{SiO}_{2}$ & $\mathrm{Al}_{2} \mathrm{O}_{3}$ & $\mathrm{P}_{2} \mathrm{O}_{5}$ & $\mathrm{TiO}_{2}$ & \\
\hline \multirow[t]{5}{*}{800} & $\mathrm{~S}_{1}$ & 25.3 & 6.94 & 9.17 & 3.69 & 0.26 & 45.4 & 13.8 & 11.4 & 0.29 & 0.52 & 26.01 \\
\hline & $\mathrm{S}_{2}$ & 14.8 & 8.68 & 5.52 & 2.92 & 1.31 & 33.2 & 27.4 & 13.9 & 2.85 & 0.72 & 44.87 \\
\hline & $\mathrm{S}_{3}$ & 10.8 & 9.47 & 4.10 & 2.45 & 1.76 & 28.6 & 31.4 & 14.7 & 4.07 & 0.75 & 50.92 \\
\hline & $\mathrm{S}_{4}$ & 8.62 & 9.94 & 3.48 & 2.25 & 1.96 & 26.3 & 34.9 & 15.8 & 4.87 & 0.79 & 56.36 \\
\hline & $\mathrm{S}_{5}$ & 4.66 & 9.99 & 2.45 & 1.14 & 2.48 & 20.7 & 40.7 & 18.0 & 6.55 & 0.81 & 66.06 \\
\hline \multirow[t]{5}{*}{900} & $\mathrm{~S}_{1}$ & 27.0 & 7.16 & 9.31 & 2.80 & 0.30 & 46.6 & 13.6 & 11.3 & 0.26 & 0.47 & 25.63 \\
\hline & $\mathrm{S}_{2}$ & 15.1 & 9.07 & 5.42 & 2.54 & 1.20 & 33.3 & 27.6 & 13.9 & 3.17 & 0.74 & 45.41 \\
\hline & $\mathrm{S}_{3}$ & 11.1 & 9.48 & 4.13 & 2.26 & 1.72 & 28.7 & 33.0 & 15.0 & 4.26 & 0.77 & 53.03 \\
\hline & $\mathrm{S}_{4}$ & 8.72 & 9.70 & 3.53 & 2.05 & 2.01 & 26.0 & 35.0 & 15.5 & 4.91 & 0.78 & 56.19 \\
\hline & $\mathrm{S}_{5}$ & 4.66 & 9.75 & 2.47 & 1.26 & 2.39 & 20.5 & 40.9 & 17.6 & 6.56 & 0.81 & 65.87 \\
\hline \multirow[t]{5}{*}{1000} & $\mathrm{~S}_{1}$ & 26.8 & 7.45 & 9.16 & 2.10 & 0.24 & 45.8 & 14.5 & 11.6 & 0.32 & 0.57 & 26.99 \\
\hline & $\mathrm{S}_{2}$ & 15.4 & 9.27 & 5.38 & 2.24 & 1.06 & 33.4 & 28.8 & 14.3 & 3.84 & 0.77 & 47.71 \\
\hline & $\mathrm{S}_{3}$ & 11.0 & 9.33 & 4.05 & 2.56 & 1.63 & 28.6 & 33.6 & 15.4 & 5.13 & 0.77 & 54.9 \\
\hline & $\mathrm{S}_{4}$ & 8.65 & 9.78 & 3.52 & 2.17 & 1.98 & 26.1 & 36.0 & 15.9 & 5.30 & 0.75 & 57.95 \\
\hline & $\mathrm{S}_{5}$ & 4.74 & 10.2 & 2.30 & 1.24 & 2.37 & 20.9 & 38.9 & 16.3 & 6.00 & 0.85 & 62.05 \\
\hline \multirow[t]{5}{*}{1100} & $\mathrm{~S}_{1}$ & 29.1 & 9.47 & 8.62 & 1.31 & 0.14 & 48.6 & 16.0 & 12.0 & 0.42 & 0.68 & 29.1 \\
\hline & $\mathrm{S}_{2}$ & 13.6 & 9.33 & 3.36 & 1.96 & 0.85 & 29.1 & 26.5 & 12.4 & 2.68 & 0.72 & 42.3 \\
\hline & $\mathrm{S}_{3}$ & 10.3 & 9.87 & 3.05 & 1.94 & 1.63 & 26.8 & 30.2 & 13.2 & 4.21 & 0.78 & 48.39 \\
\hline & $\mathrm{S}_{4}$ & 8.42 & 9.86 & 2.73 & 1.90 & 1.87 & 24.8 & 32.7 & 14.0 & 4.52 & 0.79 & 52.01 \\
\hline & $\mathrm{S}_{5}$ & 4.60 & 9.99 & 1.86 & 1.08 & 2.23 & 19.8 & 35.4 & 13.9 & 5.06 & 0.82 & 55.18 \\
\hline
\end{tabular}




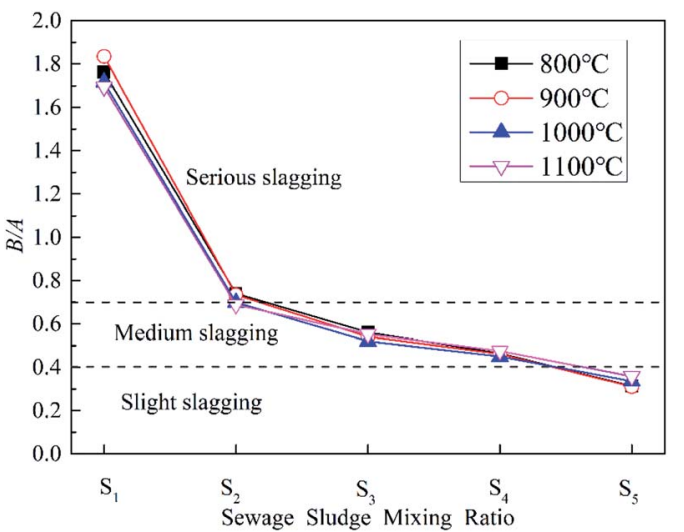

Fig. $7 B / A$ for the co-combustion ash at different temperatures and blending ratios.

$25 \%$, indicating a better ash fusibility. In this study, considering the dual influence from the blending of SS on combustion and slagging, it is apparent that $20 \%$ is the optimal blending ratio for co-combustion, which is similar to the result of previous research. $^{36}$

(2) G. $\mathrm{SiO}_{2}$ is the main component of SS ash and plays an important role in weakening the slagging behavior of ZDC during co-combustion. It is particularly necessary to study the impact from $\mathrm{SiO}_{2}$. $G$ represents the percentage of $\mathrm{SiO}_{2}$ in the alkaline oxide content of the ash, as calculated by eqn (4). The larger the value of $G$, the greater the proportion of $\mathrm{SiO}_{2}$, and the weaker the tendency for slagging. ${ }^{50}$

$$
G=\frac{\mathrm{SiO}_{2} \times 100}{\mathrm{SiO}_{2}+\mathrm{Fe}_{2} \mathrm{O}_{3}+\mathrm{CaO}+\mathrm{MgO}}
$$

The relationship between the value of $G$ and slagging is as follows: when $G>72$, there is a weak tendency for slagging; when $65<G<72$, there is a medium tendency; and when $G<65$, there is a strong tendency. Results for the calculation of $G$ for co-combustion ash at different temperatures and blending ratios are shown in Fig. 8.

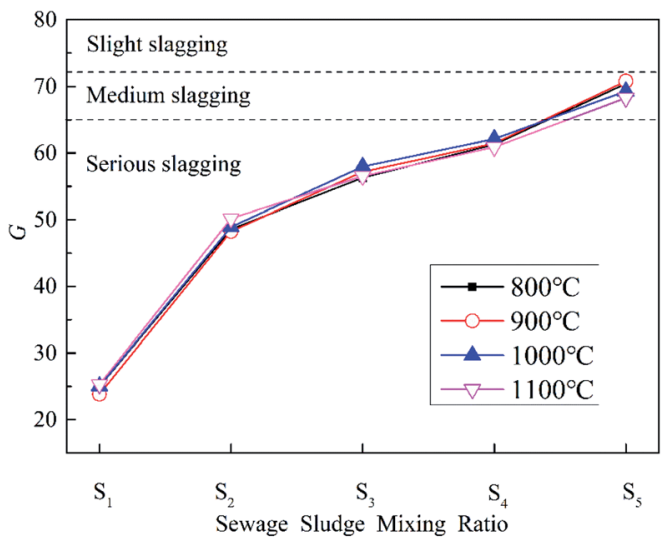

Fig. $8 \mathrm{G}$ for the co-combustion ash at different temperatures and blending ratios.
It can be seen that the trend for changes in $G$ is basically the same at different temperatures. The $\mathrm{SiO}_{2}$ content in $\mathrm{ZDC}$ ash is low, so it has a strong slagging tendency. SS ash has a medium or even weak slagging tendency, as is consistent with the results of $B / A$. The value for $G$ grows with the increase in blending ratio during co-combustion. However, the combustion ash still has a strong slagging tendency. This is because the SS blending ratio does not exceed $30 \%$ in the experiments, the amount of $\mathrm{SiO}_{2}$ in combustion ash is therefore relatively small. The results for the evaluation of slagging tendency in combustion ash could be different when using different indices $(B / A$ and $G$ ), so it is necessary to introduce other indices for further evaluation.

(3) $\mathrm{SiO}_{2} / \mathrm{Al}_{2} \mathrm{O}_{3} \cdot \mathrm{Al}_{2} \mathrm{O}_{3}$ is the second highest component in SS ash next to $\mathrm{SiO}_{2}$. A large amount of silico-alumina salt is introduced into ZDC by blending with SS. Therefore, the silicon and aluminum ratio $\left(\mathrm{SiO}_{2} / \mathrm{Al}_{2} \mathrm{O}_{3}\right)$ is used to analyze the slagging tendency of co-combustion ash. Both $\mathrm{Al}_{2} \mathrm{O}_{3}$ and $\mathrm{SiO}_{2}$ have the effect of increasing the melting point of ash and weakening slagging behavior. However, silicate reacts easily with other components to form low-temperature eutectics, such as $\mathrm{Fe}_{2} \mathrm{SiO}_{4}, \mathrm{Fe}_{3} \mathrm{Al}_{2}\left(\mathrm{SiO}_{4}\right)_{3}, \mathrm{Ca}_{3} \mathrm{Si}_{3} \mathrm{O}_{9}$ etc. ${ }^{51}$ Therefore, compared with $\mathrm{Al}_{2} \mathrm{O}_{3}$, the presence of $\mathrm{SiO}_{2}$ will lower the ash melting point and cause the formation of slagging. The relationship between $\mathrm{SiO}_{2} /$ $\mathrm{Al}_{2} \mathrm{O}_{3}$ value and slagging behavior is as follows: when $\mathrm{SiO}_{2} / \mathrm{Al}_{2} \mathrm{O}_{3}$ $<1.87$, there is a weak tendency for slagging; when $1.87<\mathrm{SiO}_{2} /$ $\mathrm{Al}_{2} \mathrm{O}_{3}<2.65$, there is medium tendency; and when $\mathrm{SiO}_{2} / \mathrm{Al}_{2} \mathrm{O}_{3}>$ 2.65 , there is a strong tendency. The results for the calculation of $\mathrm{SiO}_{2} / \mathrm{Al}_{2} \mathrm{O}_{3}$ in co-combustion ash at different temperatures and blending ratios are shown in Fig. 9.

Considering the effect of the blending of SS on slagging, it is apparent that $\mathrm{SiO}_{2} / \mathrm{Al}_{2} \mathrm{O}_{3}$ gradually increases with an increase in the blending ratio, and the tendency for slagging also changes from weak to strong, indicating that excessive blending with SS does not necessarily weaken slagging behavior. This further proves that there is an optimal ratio for blending SS. As the $\mathrm{SiO}_{2} / \mathrm{Al}_{2} \mathrm{O}_{3}$ ratio does not take into consideration the influence of the alkaline oxide content in combustion ash, the ZDC ash is evaluated as having a weak slagging tendency, which is contrary to accepted fact. This is probably caused by the relatively low

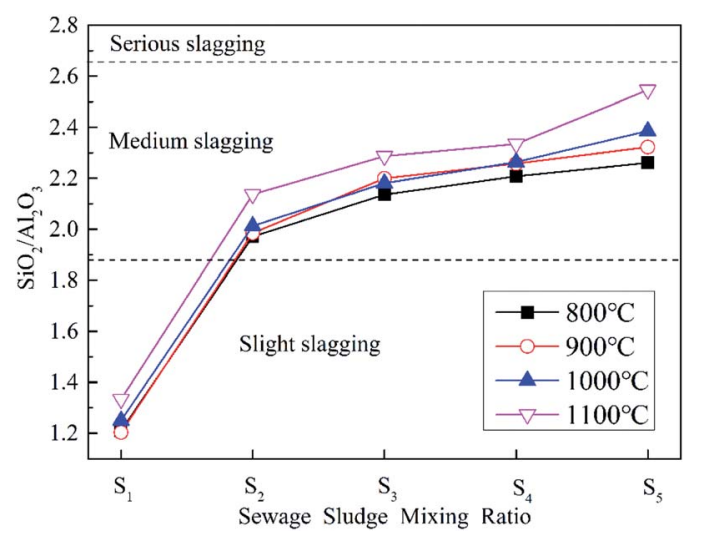

Fig. $9 \mathrm{SiO}_{2} / \mathrm{Al}_{2} \mathrm{O}_{3}$ for the co-combustion ash at different temperatures and blending ratios. 
$\mathrm{SiO}_{2}$ content within the $\mathrm{ZDC}$, and low temperature eutectics are not easily formed.

The above results verify that $B / A$ and $\mathrm{SiO}_{2} / \mathrm{Al}_{2} \mathrm{O}_{3}$ are more suitable for analyzing the slagging tendency of co-combustion ash due to the influence of combustion ash components and other factors. The results from these indices are consistent with each other, but significantly deviate from the results of $G$.

\section{Conclusions}

The effect of blending SS with ZDC on combustion and the behavior of ash slagging are investigated in this study. The combustion of fixed carbon plays a major role during ZDC combustion, while the volatiles combustion is important for SS.

There is an appropriate blending ratio of SS which could enhance the co-combustion. With an increase in the blending ratio of SS, the strong slagging behavior during ZDC combustion could reduce to medium or slight degree. Considering the dual influence of SS blending on the combustion and slagging behaviors, under the experimental conditions in this study, the blending ratio of SS is suggested to be $20 \%$.

\section{Conflicts of interest}

There are no conflicts to declare.

\section{Abbreviations}

$\mathrm{SS}$
$\mathrm{TG}$
$\mathrm{ZDC}$
AAEMs
$\mathrm{XRF}$
$B / A$
$C$
$G$
$S$
$\mathrm{SiO}_{2} / \mathrm{Al}_{2} \mathrm{O}_{3}$
$\mathrm{SI}$
$\mathrm{CFB}$
$\mathrm{FM}$
$\mathrm{FWO}$
$T_{\mathrm{i}}$
$T_{\mathrm{h}}$
$\alpha$
$E_{\mathrm{m}}$

Sewage sludge
Thermogravimetry
Zhundong coal
Alkali and alkaline earth metals
X-ray fluorescence
Alkali acid ratio
Ignition index
Silicon ratio
Comprehensive combustion index
Silica-alumina ratio
Stable combustion index
Circulating fluidized bed
Friedman
Flynn-Wall-Ozawa
Ignition temperature
Burnout temperature
Conversion rate
Activation energy

\section{Acknowledgements}

We gratefully acknowledge the financial support provided by the National Key Technologies Research and Development Program (No. 2018YFB0905104), National Natural Science Funds for Young Scholars of China (No.51806033) and Jilin Provincial Science and Technology Development Program (No. 20180201008SF, 20190201096JC).

\section{Notes and references}

1 S. Kyi and B. L. Chadwick, Fuel, 1999, 78, 845-855.

2 X. Zhang, H. Zhang and Y. Na, Procedia Eng., 2015, 102, 305314.

3 X. Wang, Z. Xu, B. Wei, L. Zhang, H. Tan, T. Yang, H. Mikulčić and N. Duić, Appl. Therm. Eng., 2015, 80, 150159.

4 H. Wang, S. Guo, L. Yang, X. Wei, S. Zhang and S. Wu, Fuel Process. Technol., 2017, 155, 134-143.

5 G. Li, C. Wang, Y. Yan, X. Jin, Y. Liu and D. Che, J. Energy Inst., 2016, 89, 48-56.

6 Y. Yuan, S. Li and Q. Yao, Proc. Combust. Inst., 2015, 35, 2339-2346.

7 X. Zhang, H. Zhang and Y. Na, Procedia Eng., 2015, 102, 305314.

8 L. Xu, H. Liu, D. Zhao, Q. Cao and S. Wu, Fuel, 2018, 233, 2936.

9 A. R. Manzoori and P. K. Agarwal, Fuel, 1992, 71, 513-522.

10 G. Song, W. Song, X. Qi and Q. Lu, Energy Fuels, 2016, 30, 3473-3478.

11 X. Wang, Z. Xu, B. Wei, L. Zhang, H. Tan, T. Yang, H. Mikulčić and N. Duić, Appl. Therm. Eng., 2015, 80, 150159.

12 G. Song, X. Qi, W. Song, S. Yang, Q. Lu and W. Nowak, Fuel, 2016, 186, 140-149.

13 Y. Liu, L. Cheng, J. Ji and W. Zhang, Appl. Therm. Eng., 2019, 149, 520-527.

14 J. Li, M. Zhu, Z. Zhang, K. Zhang, G. Shen and D. Zhang, Fuel Process. Technol., 2016, 149, 176-186.

15 H. Zhou and W. Ma, Appl. Therm. Eng., 2017, 126, 689-701.

16 E. Gomez, D. A. Rani and C. R. Cheeseman, J. Hazard. Mater., 2009, 161, 614-626.

17 Z. Wang, C. Hong, Y. Xing, Y. Li and M. Jia, Waste Manage., 2018, 74, 288-296.

18 A. Kijo-Kleczkowska, K. Środa, M. Kosowska-Golachowska, T. Musiał and K. Wolski, Waste Manage., 2015, 46, 459-471.

19 D. Fytili and A. Zabaniotou, Renewable Sustainable Energy Rev., 2008, 12, 116-140.

20 H. Xiao, X. Ma and Z. Lai, Appl. Energy, 2009, 86, 1741-1745.

21 A. Magdziarz and M. Wilk, Energy Convers. Manage., 2013, 75, 425-430.

22 S. H. Deng, X. B. Wang, H. Z. Tan, H. Mikulčić and F. X. Yang, Thermochim. Acta, 2016, 633, 69-76.

23 A. S. Akdağ, A. Onur, A. T. Atimtay and F. D. Sanin, Energy, 2018, 158, 417-426.

24 M. Otero, X. Gómez, A. I. García and A. Morán, Chemosphere, 2007, 69, 1740-1750.

25 M. B. Folgueras, R. M. Díaz, J. Xiberta and I. Prieto, Fuel, 2003, 82, 2051-2055.

26 J. M. Park, S. Keel, J. Yun and J. H. Yun, Korean J. Chem. Eng., 2017, 34, 1-7.

27 R. Wang, Z. Zhao, Q. Yin and J. Liu, Fuel, 2017, 199, 578-586.

28 R. Hao, Z. Zhang, Q. Zeng, Y. Mao, H. He, X. Mao, F. Yang and Y. Zhao, Energy, 2018, 153, 776-787. 
29 L. Wang, G. Skjevrak, J. E. Hustad and M. G. Grønli, Fuel Process. Technol., 2012, 96, 88-97.

30 L. Wang, G. Skjevrak, J. E. Hustad and M. G. Grønli, Energy Fuels, 2011, 25, 5775-5785.

31 A. Grimm, N. Skoglund, D. Boström and M. Öhman, Energy Fuels, 2011, 25, 937-947.

32 H. Li, K. Han, Q. Wang and C. Lu, Energy Fuels, 2015, 29, 2555-2563.

33 Q. Zhang, H. Liu, Y. Qian, M. Xu, W. Li and J. Xu, Fuel Process. Technol., 2013, 110, 218-226.

34 R. W. Bryers, Prog. Energy Combust. Sci., 1996, 22, 29-120.

35 A. Kijo-Kleczkowska, K. Środa, M. Kosowska-Golachowska, T. Musiał and K. Wolski, Waste Manage., 2016, 53, 165-181.

36 X. Qi, G. Song, W. Song, S. Yang and Q. Lu, J. Energy Inst., 2018, 91, 397-410.

37 S. Niu, M. Chen, Y. Li and F. Xue, Fuel, 2016, 178, 129-138.

38 S. A. Scott, J. S. Dennis, J. F. Davidson and A. N. Hayhurst, Fuel, 2006, 85, 1248-1253.

39 Y. Z. Li, X. Q. Ma, Y. T. Tang and Z. L. Cai, Adv. Mater. Res., 2013, 772, 487-494.

40 Y. Liao and X. Ma, Appl. Energy, 2010, 87, 3526-3532.
41 H. Mikulcic, E. V. Berg, M. Vujanovic and N. Duic, Waste Manage. Res., 2014, 32, 661-669.

42 N. Zhang, X. A. Ning and J. B. Zhou, Appl. Mech. Mater., 2011, 55-57, 1132-1137.

43 R. N. Coimbra, S. Paniagua, C. Escapa, L. F. Calvo and M. Otero, Waste Biomass Valorization, 2016, 7, 995-1006.

44 H. Liu, M. Lu, P. Xu and Q. Wang, J. Therm. Anal. Calorim., 2017, 130, 1191-1200.

45 R. N. Coimbra, S. Paniagua, C. Escapa, L. F. Calvo and M. Otero, Renewable Energy, 2015, 83, 1050-1058.

46 Y. Lin, Y. Liao, Z. Yu, S. Fang and X. Ma, Thermochim. Acta, 2017, 653, 71-78.

47 Z. H. Zhao, R. K. Wang, J. H. Wu, Q. Q. Yin and C. B. Wang, Energy, 2019, 171, 809-818.

48 M. Pronobis, Biomass Bioenergy, 2005, 28, 375-383.

49 J. C. V. Dyk, Miner. Eng., 2006, 19, 280-286.

50 G. Dunnu, J. Maier and G. Scheffknecht, Fuel, 2010, 89, 1534-1540.

51 R. Heikkinen, R. S. Laitinen, T. Patrikainen, M. Tiainen and M. Virtanen, Fuel Process. Technol., 1998, 56, 69-80. 